\title{
Experimental research method when developing a mathematical model for calculating cutting speed in the course of turning steels with a coated tool
}

\author{
Zhanna Tikhonova ${ }^{1, *}$, Evgeniy Frolov ${ }^{1}$, Dmitriy Krainev ${ }^{1}$ and Alexander Plotnikov ${ }^{1}$ \\ ${ }^{1}$ Volgograd state technical university, Department of mechanical engineering technology, 400005, \\ Linine Ave. 28, Volgograde, Russian Federation
}

\begin{abstract}
The article is devoted to the description of the experimental research method when developing a mathematical model for calculating the cutting speed based on information from the cutting zone obtained during the test run in the process of turning using steel coated tools as an example. This paper also presents the results of an experimental study which prove the effectiveness of applying the obtained mathematical dependence.
\end{abstract}

In modern computer-aided design systems of technological processes (CAD TP) cutting conditions are either selected according to empirical tables proposed by tool manufacturers or calculated according to mathematical relationships (1). A major shortcoming of both methods is a significant and poorly predicted deviation of the actual period of tool life from the period forecast in the calculations [1]. The indicated drawback negatively affects the reliability of metal-cutting equipment with CNC making it practically impossible in the conditions of "digital factories". Thus, the present work is devoted to the development of a mathematical model for the cutting speed calculation in the course of turning a workpiece with coated tools at the design stage of the technological process.

Consider the analytical dependence:

$$
V=\frac{C_{v}}{T^{m} t^{x} s^{y}} K_{v}
$$

where $T$ is the specified durability in minutes, $s$ is the feed in $\mathrm{mm} / \mathrm{rev}$; $t$ is the cutting depth in $\mathrm{mm}, V$ is the speed in $\mathrm{m} / \mathrm{min}$; $C_{v}$ is a dimensionless coefficient; $m, x, y$ are exponents of power; $K_{v}$ is the resulting correction dimensionless coefficient equal to the product of a number of correction factors that take into account:

$$
K_{V}=K_{м} \cdot K_{\text {и }} \cdot K_{\phi} \cdot K_{m} \cdot K_{\text {ж }} \cdot K_{п} \cdot K_{\text {о }}
$$

where $K_{M}$ is a coefficient of machinability;

* Corresponding author: tikhonovazhs@gmail.com 
$K_{t}$ is a coefficient taking into account the properties of the cutting tool material;

$K_{\varphi}$ is a coefficient taking into account the influence of the angle in the plan $\varphi$;

$K_{m}$ is a coefficient taking into account the type of machining (cross or longitudinal turning, boring, etc.);

$K_{r}$ is a coefficient taking into account the rigidity of the technological system;

$K_{s}$ is a coefficient taking into account the state of the machined surface;

$K_{c f}$ is a coefficient taking into account the influence of cutting fluid.

In this analytical dependence $C_{v}$ and $K_{v}$ are dimensionless quantities that have no physical meaning. Nevertheless, many mathematical models, in particular (1), suggest that $C_{v}$ is a quantity that depends on both the properties of the tool and the properties of the material being machined. However, in this dependence (1), on the one hand, we use average data on the properties of the machined and tool material from the possible range of physicomechanical properties dispersion acceptable by the technical condition. But on the other hand, we have the coefficient $C_{v}$, which does not take into account the probabilistic law of the formation of contact pairs, and this fact leads to great errors in calculating the cutting speed and predicting a given durability. The main objective of this study is to stop using averaged values when calculating cutting speed and predicting resistance and to start employing operational information about the changing properties of each tool-workpiece contact pair. In this case, the product of the coefficients $C_{v}$ and $K_{v}$ is not a constant, but a variable quantity, depending on the properties of each contact pair.

It is proposed to determine the value of the product of the coefficients $C_{v}$ and $\mathrm{Kv}$ as the characteristics for the combination of physicomechanical and thermophysical properties in the contact pair using the thermo-emf magnitude of the test run [1]. With the established relationship of the indicated coefficients with the thermoelectric properties of the contact pair, their value obtains physical meaning and allows us to take into account current variation in the properties of the contact pair in dependence (1), where it is proposed to introduce an additional information parameter for thermo-emf $(E)$.

To identify such a relationship, it was necessary to process the results of wear tests in various pairs of "carbon steels - coated hard alloys": Steel grade 45 - TS20RT, 40X TS20RT, ShH15 - TS20RT.

Before the beginning of wear tests, the thermo-emf of the test run for each contact pair was preliminary measured. The chamfer wear on the back face was brought to $0.5 \mathrm{~mm}$ for the semi-finishing step. At this level of wear, the tool life was recorded from the beginning of testing at various cutting speeds, feeds and cutting depths [2]. The product of the coefficients $C_{v}$ and $K_{v}$ was calculated on the basis of the formula (2). The special feature of this calculation method was the fact that this formula did not take into account corrections for tool geometry, strength properties of the machined material, cutting properties of the carbide matrix, as well as the composition of wear-resistant coating, the number of layers of the components of this coating and also didn't consider the method of its application. In this case, the thermo-emf of the test run $E$ was taken into account as a complex criterion for evaluating the properties of contact pairs. The value of the product of the coefficients $C_{v}$ and $K_{v}$ was calculated by the following mathematical relationship

$$
C_{v}=V \cdot t^{x} \cdot s^{y} \cdot T^{m}
$$

where $T$ is the actual durability of the carbide tool with a wear-resistant coating obtained from the experience, min.

This method stipulates that at the stage of semi-finishing turning cutting speed calculation is preceded by a test cutting operation, i.e. we preliminary machine the metal (steel workpiece) and measure thermo-emf in the pair "tool - workpiece". Next, by the thermo-emf value of a given pair and the operational parameters of the technological 
process (feed $s$, cutting depth $t$ and specified resistance $T$ ), it is necessary to determine the allowable cutting speed, which ensures the specified durability.

The mathematical model proposed in this work was made with the help of regression analysis. As it is noted in [3] the essence of this analysis is to determine the best parameters of the regression model. The main criterion for the effective determination of the best parameters is maximum convergence of the calculation results (according to the regression model) with the experimental ones.

Such mathematical models as polynomial, power and exponential were adopted as regression models for the analysis. When planning the experiment and in its course, each factor (listed in Table 1) was assigned three levels: the lower level (-1), the middle level $(0)$, and the upper level $(+1)$.

Table 1. Levels of factors and variability intervals at semi-finishing turning

\begin{tabular}{|c|c|c|c|c|c|c|c|}
\hline \multirow{2}{*}{ Factors } & \multirow{2}{*}{ Designation } & \multirow{2}{*}{$\begin{array}{c}\text { Unit of } \\
\text { measurement }\end{array}$} & \multirow{2}{*}{$\begin{array}{c}\text { Symbolic } \\
\text { notation }\end{array}$} & \multicolumn{3}{|c|}{ Levels of factors } & \multirow{2}{*}{$\begin{array}{l}\text { Variability } \\
\text { intervals }\end{array}$} \\
\hline & & & & -1 & 0 & +1 & \\
\hline \multicolumn{8}{|c|}{ Semi-finishing turning } \\
\hline $\begin{array}{c}\text { Thermo-emf value } \\
\text { of a "tool- } \\
\text { workpiece" } \\
\text { thermocouple }\end{array}$ & $E$ & $m V$ & $X_{1}$ & 7,16 & 8,74 & 10,42 & 1,5 \\
\hline Cutting depth & $t$ & $\mathrm{~mm}$ & $X_{2}$ & 0,5 & 1 & 1,5 & 0,5 \\
\hline Feed & $S$ & $\mathrm{~mm} / \mathrm{rev}$ & $X_{3}$ & 0,11 & 0,195 & 0,28 & 0,085 \\
\hline Cutting speed & $V$ & $\mathrm{~m} / \mathrm{min}$ & $X_{4}$ & 100 & 160 & 220 & 60 \\
\hline
\end{tabular}

Technological modes of semi-finishing turning were selected in accordance with the data given in the references [4], [5], [6], [7].

Mutual combinations of the levels of factor during a full factorial experiment determine the experimental plan for a particular regression model. Table 2 shows the so-called experiment planning matrix for semi-finishing turning operations respectively.

Table 2. Experiment Planning Matrix (abbreviated) at semi-finishing turning

\begin{tabular}{|c|c|c|c|c|c|c|c|c|c|}
\hline \multirow{2}{*}{$\begin{array}{l}\text { Experiment } \\
\text { number }\end{array}$} & \multicolumn{5}{|c|}{ Real values of experimental data } & \multicolumn{4}{|c|}{ Levels of factors } \\
\hline & $E$ & $t$ & $S$ & $V$ & $T$ & $X_{1}$ & $X_{2}$ & $X_{3}$ & $X_{4}$ \\
\hline 1 & 7.16 & 0.50 & 0.11 & 100.00 & 28.00 & -1 & -1 & -1 & -1 \\
\hline 2 & 7.16 & 0.50 & 0.11 & 160.00 & 25.00 & -1 & -1 & -1 & 0 \\
\hline 3 & 7.16 & 0.50 & 0.11 & 220.00 & 22.00 & -1 & -1 & -1 & +1 \\
\hline & & & & & & & & & \\
\hline 40 & 8.74 & 1.00 & 0,195 & 100.00 & 20.00 & 0 & 0 & 0 & -1 \\
\hline 41 & 8.74 & 1.00 & 0,195 & 160.00 & 18.00 & 0 & 0 & 0 & 0 \\
\hline 42 & 8.74 & 1.00 & 0,195 & 220.00 & 15.00 & 0 & 0 & 0 & +1 \\
\hline & & & & & & & & & \\
\hline 79 & 10.42 & 1.50 & 0.28 & 100.00 & 10.00 & +1 & +1 & +1 & -1 \\
\hline 80 & 10.42 & 1.50 & 0.28 & 160.00 & 8.00 & +1 & +1 & +1 & 0 \\
\hline 81 & 10.42 & 1.50 & 0.28 & 220.00 & 8.00 & +1 & +1 & +1 & +1 \\
\hline
\end{tabular}

When considering the question of assessing the degree of influence of factors on the response function, it was proposed to use a correlation coefficient, which allows us to establish the probability of a linear relationship between the statistical samples of the response function and each individual factor. 
Table 3 shows the values of the correlation coefficients between the statistical samples of the response function and each individual factor, as well as the correlation coefficients (coupled) between the statistical samples of each possible combination of factors with each other.

Table 3. The value of the correlation coefficients of statistical samples while turning

\begin{tabular}{|c|c|c|c|}
\hline \multicolumn{2}{|c|}{$\begin{array}{c}\text { The values under } \\
\text { comparison }\end{array}$} & $\begin{array}{c}\text { The value of the } \\
\text { correlation coefficient }\end{array}$ & $\begin{array}{c}\text { The existence of linear } \\
\text { relationship }\end{array}$ \\
\hline$X_{1}$ & $T$ & $-0,5664$ & $\begin{array}{c}\text { probable } \\
\text { (decreasing) }\end{array}$ \\
\hline$X_{2}$ & $T$ & $-0,4787$ & $\begin{array}{c}\text { improbable } \\
\text { (decreasing) }\end{array}$ \\
\hline$X_{3}$ & $T$ & $-0,3075$ & $\begin{array}{c}\text { improbable } \\
\text { (decreasing) }\end{array}$ \\
\hline$X_{4}$ & $T$ & $-0,4053$ & $\begin{array}{c}\text { improbable } \\
\text { (decreasing) }\end{array}$ \\
\hline$X_{1}$ & $X_{2}$ & 0 & doesn't exist \\
\hline$X_{1}$ & $X_{3}$ & 0 & doesn't exist \\
\hline$X_{1}$ & $X_{4}$ & 0 & doesn't exist \\
\hline$X_{2}$ & $X_{3}$ & 0 & doesn't exist \\
\hline$X_{2}$ & $X_{4}$ & 0 & doesn't exist \\
\hline$X_{3}$ & $X_{4}$ & 0 & doesn't exist \\
\hline
\end{tabular}

Using the data from Table 3 we can see that there is no mutual influence and paired relationship between the factors. This fact is a prerequisite for conducting a full-factor experiment and obtaining a reliable mathematical model, and each of the selected factors of the regression model affects the response function $T$.

In order to eliminate errors in the regression models connected with different scales of the real values of factors, it is necessary to perform a normalization operation. Table 4 shows the examples of the normalized values of the factors and response functions for three specifications under consideration (polynomial, power, and exponential) in the process of a semi-finishing turning operation.

Table 4. Normalized values of factors and response functions in the process of semi-finishing turning of steels

\begin{tabular}{|c|c|c|c|c|c|c|c|c|c|c|c|}
\hline \multirow{3}{*}{ № } & \multirow{3}{*}{$X_{0}$} & \multicolumn{5}{|c|}{ Natural values } & \multicolumn{5}{|c|}{ Normalized values } \\
\hline & & \multicolumn{4}{|c|}{ Factors } & Function & \multicolumn{4}{|c|}{ Factors } & \multirow{2}{*}{$\begin{array}{c}\text { Function } \\
Y\end{array}$} \\
\hline & & E & $t$ & $S$ & V & $T$ & $X_{1}$ & $X_{2}$ & $X_{3}$ & $X_{4}$ & \\
\hline \multicolumn{12}{|c|}{ Linear model } \\
\hline 1 & 1 & 7,16 & 0,5 & 0,11 & 100 & 28.00 & $\begin{array}{c}- \\
0.715\end{array}$ & $\begin{array}{c}- \\
0.917\end{array}$ & $\begin{array}{c}- \\
0.895\end{array}$ & -0.868 & 0.763 \\
\hline 2 & 1 & 7,16 & 0,5 & 0,11 & 160 & 25.00 & $\begin{array}{c}- \\
0.715\end{array}$ & $\begin{array}{c}- \\
0.917\end{array}$ & $\begin{array}{c}- \\
0.895\end{array}$ & -0.079 & 0.509 \\
\hline 3 & 1 & 7,16 & 0,5 & 0,11 & 220 & 22.00 & $\begin{array}{c}- \\
0.715\end{array}$ & $\begin{array}{c}- \\
0.917\end{array}$ & $\begin{array}{c}- \\
0.895\end{array}$ & 0.711 & 0.254 \\
\hline \\
\hline 40 & 1 & 8,74 & 1 & 0,195 & 100 & 20.00 & $\begin{array}{c}- \\
0.085\end{array}$ & $\begin{array}{c}- \\
0.083\end{array}$ & $\begin{array}{c}- \\
0.081\end{array}$ & -0.868 & 0.085 \\
\hline 41 & 1 & 8,74 & 1 & 0,195 & 160 & 18.00 & $\begin{array}{c}- \\
0.085\end{array}$ & $\begin{array}{c}- \\
0.083\end{array}$ & $\begin{array}{c}- \\
0.081\end{array}$ & -0.079 & -0.085 \\
\hline 42 & 1 & 8,74 & 1 & 0,195 & 220 & 15.00 & $\begin{array}{c}- \\
0.085\end{array}$ & $\begin{array}{c}- \\
0.083\end{array}$ & $\begin{array}{c}- \\
0.081\end{array}$ & 0.711 & -0.339 \\
\hline \\
\hline 79 & 1 & 10,42 & 1,5 & 0,28 & 100 & 10.00 & 0.585 & 0.750 & 0.732 & -0.868 & -0.763 \\
\hline 80 & 1 & 10,42 & 1,5 & 0,28 & 160 & 8.00 & 0.585 & 0.750 & 0.732 & -0.079 & -0.932 \\
\hline
\end{tabular}




\begin{tabular}{|c|c|c|c|c|c|c|c|c|c|c|c|}
\hline 81 & 1 & 10,42 & 1,5 & 0,28 & 220 & 8.00 & 0.585 & 0.750 & 0.732 & 0.711 & -0.932 \\
\hline \multicolumn{12}{|c|}{ Power model } \\
\hline 1 & 1 & 7,16 & 0,5 & 0,11 & 100 & 28.00 & $\begin{array}{c}- \\
0.634\end{array}$ & $\begin{array}{c}- \\
0.838\end{array}$ & $\begin{array}{c}- \\
0.814\end{array}$ & -0.787 & 0.869 \\
\hline 2 & 1 & 7,16 & 0,5 & 0,11 & 160 & 25.00 & $\begin{array}{c}- \\
0.634\end{array}$ & $\begin{array}{c}- \\
0.838\end{array}$ & 0.814 & 0.163 & 0.713 \\
\hline 3 & 1 & 7,16 & 0,5 & 0,11 & 220 & 22.00 & $\begin{array}{c}- \\
0.634\end{array}$ & $\begin{array}{c}- \\
0.838\end{array}$ & $\begin{array}{c}- \\
0.814\end{array}$ & 0.807 & 0.537 \\
\hline \multicolumn{12}{|c|}{$\ldots$} \\
\hline 40 & 1 & 8,74 & 1 & 0,195 & 100 & 20.00 & 0.058 & 0.229 & 0.195 & -0.787 & 0.406 \\
\hline 41 & 1 & 8,74 & 1 & 0,195 & 160 & 18.00 & 0.058 & 0.229 & 0.195 & 0.163 & 0.261 \\
\hline 42 & 1 & 8,74 & 1 & 0,195 & 220 & 15.00 & 0.058 & 0.229 & 0.195 & 0.807 & 0.010 \\
\hline \multicolumn{12}{|c|}{$\ldots$} \\
\hline 79 & 1 & 10,42 & 1,5 & 0,28 & 100 & 10.00 & 0.669 & 0.853 & 0.832 & -0.787 & -0.548 \\
\hline 80 & 1 & 10,42 & 1,5 & 0,28 & 160 & 8.00 & 0.669 & 0.853 & 0.832 & 0.163 & -0.855 \\
\hline 81 & 1 & 10,42 & 1,5 & 0,28 & 220 & 8.00 & 0.669 & 0.853 & 0.832 & 0.807 & -0.855 \\
\hline \multicolumn{12}{|c|}{ Exponential model } \\
\hline 1 & 1 & 6,0 & 7,16 & 0,5 & 0,11 & 28.00 & $\begin{array}{c}- \\
0.715\end{array}$ & $\begin{array}{c}- \\
0.917\end{array}$ & $\begin{array}{c}- \\
0.895\end{array}$ & -0.868 & 0.869 \\
\hline 2 & 1 & 6,0 & 7,16 & 0,5 & 0,11 & 25.00 & $\begin{array}{c}- \\
0.715\end{array}$ & $\begin{array}{c}- \\
0.917\end{array}$ & $\begin{array}{c}- \\
0.895\end{array}$ & -0.079 & 0.713 \\
\hline 3 & 1 & 6,0 & 7,16 & 0,5 & 0,11 & 22.00 & $\begin{array}{c}- \\
0.715\end{array}$ & $\begin{array}{c}- \\
0.917\end{array}$ & $\begin{array}{c}- \\
0.895\end{array}$ & 0.711 & 0.537 \\
\hline \\
\hline 40 & 1 & 8,74 & 1 & 0,195 & 100 & 20.00 & $\begin{array}{c}- \\
0.085\end{array}$ & $\begin{array}{c}- \\
0.083 \\
\end{array}$ & $\begin{array}{c}- \\
0.081 \\
\end{array}$ & -0.868 & 0.406 \\
\hline 41 & 1 & 8,74 & 1 & 0,195 & 160 & 18.00 & 0.085 & 0.083 & 0.081 & -0.079 & 0.261 \\
\hline 42 & 1 & 8,74 & 1 & 0,195 & 220 & 15.00 & $\begin{array}{c}- \\
0.085\end{array}$ & $\begin{array}{c}- \\
0.083\end{array}$ & $\overline{-}-\overline{081}$ & 0.711 & 0.010 \\
\hline \\
\hline 79 & 1 & 10,42 & 1,5 & 0,28 & 100 & 10.00 & 0.585 & 0.750 & 0.732 & -0.868 & -0.548 \\
\hline 80 & 1 & 10,42 & 1,5 & 0,28 & 160 & 8.00 & 0.585 & 0.750 & 0.732 & -0.079 & -0.855 \\
\hline 81 & 1 & 10,42 & 1,5 & 0,28 & 220 & 8.00 & 0.585 & 0.750 & 0.732 & 0.711 & -0.855 \\
\hline
\end{tabular}

It is generally accepted that the influence of errors on the experimental process is maximum. In this regard, the pseudo-factor $X_{0}$ is added to the matrix of experimental studies, and it is equal to 1 for all the experiments $\left(X_{0}=1\right)$. For this factor, the regression coefficient $b_{0}$ is calculated. In a normalized state, it shows the degree of influence of errors on experiments, and when performing the operation of reverse normalization, it compensates for the error connected with the difference in the scales of significant factors $X_{i}$

Table 5. Regression coefficients of basic specifications in the process of semi-finishing turning of steels

\begin{tabular}{|c|c|c|c|c|c|c|}
\hline \multirow{2}{*}{$\begin{array}{c}\text { Model adequacy } \\
\%\end{array}$} & \multirow{2}{*}{ Model type } & \multicolumn{5}{|c|}{ Factors of regression models } \\
\cline { 3 - 7 } & & $X_{0}$ & $X_{1}(E)$ & $X_{2}(t)$ & $X_{3}(S)$ & $X_{4}(V)$ \\
\hline \multicolumn{7}{|c|}{ Semi-finishing turning } \\
\hline \multirow{2}{*}{$\begin{array}{c}\text { Regression } \\
\text { coefficients of } \\
\text { model bi }\end{array}$} & linear & -0.314 & -0.306 & -0.199 & -0.110 & -0.168 \\
\cline { 2 - 7 } & power & -0.017 & -0.412 & -0.259 & -0.155 & -0.244 \\
\cline { 2 - 7 } $\begin{array}{c}\text { Regression } \\
\text { coefficients } \\
\text { (significant) Bi }\end{array}$ & exponential & -0.017 & -0.403 & -0.273 & -0.160 & -0.238 \\
\cline { 2 - 7 } & linear & -0.314 & -0.306 & -0.199 & -0.110 & -0.168 \\
\cline { 2 - 7 } & power & -0.017 & -0.412 & -0.259 & -0.155 & -0.244 \\
\hline
\end{tabular}


Since the analysis of the data obtained in Table 5 shows that all factors are statistically significant, then the equality $T^{\prime}=T^{\prime \prime}$ is valid for the response function.

Table 6. The results of modeling process for semi-finishing turning

\begin{tabular}{|c|c|c|c|c|c|c|c|}
\hline \multirow{2}{*}{$\begin{array}{l}\text { Number of } \\
\text { the } \\
\text { experiment }\end{array}$} & $\begin{array}{l}\text { Response } \\
\text { Function }\end{array}$ & \multicolumn{2}{|c|}{ Linear model } & \multicolumn{2}{|c|}{ Power model } & \multicolumn{2}{|c|}{ Exponential model } \\
\hline & $\underset{\min }{T}$ & $\begin{array}{l}T \text { ", } \\
\text { min }\end{array}$ & $\begin{array}{c}\text { calculation } \\
\text { accuracy , } \\
\%\end{array}$ & $\begin{array}{l}T \text { ", } \\
\text { min }\end{array}$ & $\begin{array}{c}\text { calculation } \\
\text { accuracy, } \\
\%\end{array}$ & $\begin{array}{l}T \text { ", } \\
\min \end{array}$ & $\begin{array}{c}\text { calculation } \\
\text { accuracy, } \\
\%\end{array}$ \\
\hline 1 & 28,00 & 0,332 & 18,16 & 0,780 & 6,25 & 0,872 & 0,25 \\
\hline 2 & 25,00 & 0,199 & 14,62 & 0,548 & 11,30 & 0,684 & 2,06 \\
\hline 3 & 22,00 & 0,066 & 10,11 & 0,391 & 10,10 & 0,496 & 2,92 \\
\hline 40 & 20,00 & $-0,116$ & 11,85 & 0,062 & 22,12 & 0,260 & 10,05 \\
\hline 41 & 18,00 & $-0,249$ & 10,77 & $-0,170$ & 26,90 & 0,072 & 12,82 \\
\hline 42 & 15,00 & $-0,382$ & 3,39 & $-0,328$ & 21,76 & $-0,116$ & 8,74 \\
\hline 79 & 10,00 & $-0,576$ & 22,01 & $-0,450$ & $\begin{array}{l}7,36 \\
\end{array}$ & $-0,368$ & 13,96 \\
\hline 80 & 8,00 & $-0,709$ & 32,90 & $-0,682$ & 13,37 & $-0,556$ & 24,26 \\
\hline 81 & 8,00 & $-0,842$ & 13,29 & $-0,840$ & 1,12 & $-0,744$ & $\begin{array}{l}8,39 \\
\end{array}$ \\
\hline
\end{tabular}

For the further development of mathematical support, it is necessary to verify the adequacy of the models which were used in the research according to the results of the obtained experimental and calculated data. To assess the adequacy of the models used in the apparatus of mathematical statistics, it is quite effective to apply the Fisher criterion (or F-criterion) [8], [9], [10], [11]. The use of this criterion is supported by the fact that it allows us to evaluate the reliability of the models rather easily (without additional parameters), but at the same time rather accurately (since the parameters of standard deviations of the statistical samples are applied). To assess the accuracy of the modeling process using three mathematical models we summarized the results of comparing regression models during semi-finishing turning in Table 6 .

Having analyzed the data in Table 7 we concluded that the power model should be considered the most effective one during all four types of machining, since the mean relative error in calculating parameter $T$ according to the power model is minimal, in contrast to the mean relative error in calculation using other specifications (linear and exponential models).

Table 7. Comparison of regression models for semi-finishing turning

\begin{tabular}{|c|c|c|c|}
\hline \multirow{2}{*}{ Estimated Parameter } & \multicolumn{3}{|c|}{ Model specification } \\
\cline { 2 - 4 } & Linear & Power & Exponential \\
\hline \multicolumn{2}{|c|}{ Semi-finishing turning } \\
\hline Validity of the model, \% & 99,75 & 99,93 & 99,97 \\
\hline Tabled value of $F$-criterion & 1,887 & 2,063 & 2,180 \\
\hline Calculated value of $F$-criterion $\left(f^{\prime}=f^{\prime}\right)$ & 1,926 & 2,112 & 2,253 \\
\hline Model adequacy & adequate & adequate & adequate \\
\hline Maximum relative error, \% & 38,29 & 27,14 & 35,91 \\
\hline Mean relative error, \% & 13,60 & 10,26 & 11,20 \\
\hline
\end{tabular}

Thus, the development of mathematical software for calculating cutting speed using a tool with a wear-resistant coating and predicting its durability in the process of semifinishing turning operations for carbon steels should be based on a power model. 
The result of the experimental research on the software development is the following formula:

$$
V=\frac{C_{V}^{\prime} \cdot E^{p_{V}}}{t^{x_{V} \cdot s} y_{V \cdot T}^{m}}
$$

where $E$ is the thermo-emf of the test run for each new contact pair, in $m V$, measured at the modes $V=100 \mathrm{~m} / \mathrm{min}, S=0.1 \mathrm{~mm} / \mathrm{rev}, t=1 \mathrm{~mm}$.

$C^{\prime}{ }_{v}=559^{2.778}, p_{v}=-2.778$ are constants, determined on the basis of durability tests.

The novelty of the proposed method lies in the fact that the value of the product of the coefficients $C_{v}$ and $K_{v}$ is taken not from the reference books, but is promptly determined for each new contact pair directly on the lathe before starting work. This value also acquires physical meaning as a generalized energy quantity which characterizes the combination of physical and mechanical (thermophysical) properties of a contact pair.

The adjusted formula for calculating cutting speed ensures that the predetermined value of the durability of the cutters coincides with the actual values within $10 \%$ with a confidence coefficient of $99.93 \%$. The proposed formula allows us to solve not only the direct problem of selection the exact value of the cutting speed but it also helps to determine (predict) the durability of the carbide tool with a wear-resistant coating on the basis of the selected cutting speed, accepted feed rates, cutting depths and thermo-emf value of the test run.

\section{References}

1. A.L. Plotnikov, Zh.S. Tikhonova, A.S. Sergeev, R.V. Volk, The designation of the cutting speed in the process of steel machining using a carbide tool with a wearresistant coating based on the preliminary operational diagnostics of the properties of contact pairs, Science based technologies in machine building, № 5 (95), pp. 9-12 (2019)

2. E.M. Frolov, Development of technological fundamentals for optimizing modes of edge cutting machining in order to increase the efficiency of CAD application in technological process, Thesis in support of candidate of Engineering Sciences: 05.03.01, Volgograd, 147 p. (2009)

3. Yu.L. Chigirinsky, N.V. Chigirinsky, Yu.M. Bykov, Stakhostic modeling in mechanical engineering: educational book, Polytechnic, Volgograd State Technical University, Volgograd, 68 p. (2002)

4. Yu.A. Novoselov, Modern methodology of optimal experimentation in the study of cutting processes, Russian Engineering Research (Vestnik Mashinostroeniya), № 5, pp. 70-76 (2008)

5. A.M. Dalsky [and others], Reference book of a mechanical engineer. In 2 vol. Vol. 1: reference book, 5th ed., revised and supplemented, Mechanical Engineering-1, Moscow, 912 p. (2001)

6. A.G. Suslov, Technology of mechanical engineering: a textbook, - 2nd ed., revised and supplemented, Mechanical Engineering, Moscow, 430 p. (2007)

7. Ralston, A.S. Patricia, Mathematical models used for adaptive control of machine tools, Mathematical and computer modeling, Vol. 11, pp. 1151-1155 (1988) 
8. Yu.P. Adler, E.V. Markova, Yu.V. Granovsky, Planning an experiment in the search for optimal conditions: a textbook, 2nd ed. revised and supplemented, Science, Moscow, 280 p. (1976)

9. P.G. Katsev, Statistical research methods of cutting tooling: a textbook, - 2nd ed., revised and supplemented, Mechanical Engineering, Moscow, 231 p. (1974)

10. L.Z. Rumshisky, Mathematical processing of experimental results: reference book, Science, Moscow, 192 p. (1971)

11. I.S. Solonin, Mathematical statistics in engineering technology: a textbook, - 2nd ed., revised and supplemented, Mechanical Engineering, Moscow, 216 p. (1972) 